\title{
Editor's Message \\ Announcing a Hydrogeology Journal theme issue on "The Future of Hydrogeology"
}

\author{
Clifford I. Voss, Executive Editor
}

What is the future of hydrogeology? Are most of the fundamental scientific problems in hydrogeology already solved? Is there really any need for more fundamental research, field measurements, or method development? Have recent scientific advances really added capabilities and tools for our practical needs? Are there any unsolved hydrogeologic questions still remaining that are vital to our optimal use and management of subsurface resources or does the remaining work only fill in some details to a story essentially already told? Will the science of hydrogeology soon become primarily an applied field, where the main task is to use known methods to solve practical problems of water supply and water quality? For other questions involving subsurface fluids, for example, waste isolation, understanding of geological processes and climate changes, are current hydrogeologic capabilities sufficient and is there any possibility for improvement? These are the types of questions that will be dealt with by an upcoming theme issue of Hydrogeology Journal (HJ) to appear in early 2005 [HJ 13(1)]. This issue will contain 10-20 peer-reviewed invited articles on both general topics and specific subject areas of hydrogeology.

In organizing this theme issue, "The Future of Hydrogeology", I am asking for your help and advice. I would appreciate your suggestions regarding the most important topics to include. In addition, I need your suggestions regarding persons who you think would be good authors for particular theme issue topics. These authors should have strong scientific-technical insight and experience from a particular area of hydrogeology. In addition, they should be farsighted, applying a broad and mature perspective concerning the theoretical and practical importance of the area they will discuss and how it connects with other areas of hydrogeology. I am hereby

Published online: 10 July 2003

(C) Springer-Verlag 2003

C. I. Voss $(\bullet)$

US Geological Survey, 431 National Center, Reston,

VA, 20192, USA

e-mail: cvoss@usgs.gov

asking you to suggest some of the best possible contributors for this issue.

It may seem early to begin the issue now, but by this time next year (mid-2004), all articles will have been submitted, reviewed, revised and finalized. So now is the time to begin the process of organizing this most important special edition.

Some articles will predict the future for a subject area of hydrogeology. These may include a brief review of history and/or the current state of the subject area as a foundation for the analysis of the particular subject area. The author should discuss whether scientific study of the area is largely complete or whether there is potential for significant new research that might be required for solving important practical or theoretical problems.

It is inevitable in any field that subject areas emerge, grow, and finally wane in activity. At all these stages, there are opportunities for interesting, creative and useful research. However, such opportunities change and may diminish as a subject area develops. The authors will analyze where in this evolution we are with respect to the subject areas, whether needs for research remain, and if so, in which directions. This speculative issue will investigate a variety of subject areas, including:

1. some that may be well past their research peak and have shifted into the realm of engineering application (possibly well-test analysis and numerical modeling, discussed below),

2. some areas that are so complex that there may be little hope of significant advances (possibly karst and fractured rock hydrology),

3. some that may as well be put aside, pending development of new measurement technologies or mathematical descriptions (possibly the study of subsurface heterogeneity), and,

4. some areas that are new and show great promise for future scientific development (possibly biological hydrogeology, ecosystems hydrogeology and hydrogeology of seismicity).

You may already find some of these statements controversial; indeed this is one objective of the issueto be thought provoking and to generate discussion among our colleagues. 
Let me give an example of the kind of analysis that could make this issue both thought provoking and pertinent. Consider an article on the topic of numerical simulation of ground-water systems. In the article, I could argue that methods for numerical simulation were already mature by the late 1970s. Although there have been refinements since then, the primary change in the power of these techniques to help us understand subsurface flow systems came not from these more recent developments in methods, but from the spectacular increase in computing capacity and speed, and in user-oriented software design that have occurred. Further, I could argue that we can expect the future to provide similar improvements in computer technology and that these will overshadow any improvements that could be made in numerical methods. Thus, the area of numerical simulation methods for ground-water modeling can be considered scientifically mature, and it is becoming part of the standard engineering practice of hydrogeology. Perhaps it no longer needs to be in the mainstream of scientific research. Numerical simulation will soon become only an applied field; the most important research is already completed and now only practical applications of the developed technology remain to be done. Indeed, this means that the research leading to the current and future state of this subject area was highly successful. An argument such as made above may either generate counter-arguments (e.g., that interesting and useful advances are being made in this area, especially concerning strongly nonlinear problems in complex 3D environments and utilization of parallel computing capabilities) or may settle the question for the future. How would you react?

Here are some hydrogeology subject areas that come to mind based on opinions of a few colleagues. This is only a start, so please feel free to criticize, add, delete, reorganize or rephrase topics, as you like.

1. Overviews and history

- New directions-problems needing solution vs. problems solved

- Hydrogeology: science (research) or engineering (application)?

- Historical perspective on hydrogeology (from ancient to current interactions, or, "What would Darcy say now?")

- Hydrogeologic predictive capability—can we really do it?

2. Physics

- Subsurface flow and transport

- Limits of Darcy's law

- Coupled effects, geochemical and mechanical processes (e.g., osmosis, diagenesis, compaction)

- Colloids and reactive transport

3. Mathematical-numerical techniques

- Numerical simulation

- Inverse modeling and calibration

- Statistical and stochastic analysis
4. Measurement and characterization

- Remote sensing (airborne, satellite and surface-based geophysical) for non-invasive characterization of the subsurface

- Surface and borehole geophysics

- Geochemistry, environmental tracers and isotopes for hydrogeologic characterization

- New tracers (e.g., biota or nanotechnological)

5. Spatial patterns, complexity and scale

- Scaling issues in site characterization and physical processes

- Dealing with heterogeneity of the subsurface

6. Understanding hydrogeologic environments

- Wetlands

- Deep-earth and role of fluids in geological processes (e.g., fault motion, abnormal compaction pressures, mineral deposit formation, origin of deep fluids)

- Ocean bottom hydrogeology

- Karst system genesis

- Fracture system genesis and role of stress in hydrology

- Extra-terrestrial "hydrogeology"

7. Water (and other subsurface) resource management and enhancement

- Mathematical/numerical optimization

- Economics of hydrogeology

- Natural attenuation of contaminants

- Coastal and arid zone saline fluids

- Artificial recharge and water re-use

- Recharge and discharge-determination and enhancement

- Unsaturated zone hydrology

8. Hydrogeology, environment and climate

- Ground-water surface-water interactions

- Hydrogeology and ecosystems

- Human impacts on hydrogeology (e.g., urbanization)

- Biological aspects of hydrogeology

- Climate-hydrogeology interaction and paleo-hydrogeology

9. Social and organizational aspects

- Hydrogeology and the humanities (social, legal, ethical issues)

- Publications, meetings and hydrogeologic forums

- Hydrogeologic education

In addition to the longer invited articles, the issue may include short (2-page) peer-reviewed essays volunteered by other authors wishing to make a statement of their views on the future of hydrogeology. Other formats may be included, such as an article combining interviews with senior hydrogeologists on their reflections and their perspectives for the future and possibly an article reporting results of a worldwide survey of opinions about hydrogeology's future. (Note that we may subsequently 
collect reader responses to the articles and viewpoints expressed in this theme issue in order to publish them in a later issue of $\mathrm{HJ}$.)

I seek and welcome your advice and ask that you contact me as soon as possible (cvoss@usgs.gov)with:
1. your suggestions concerning format and topics of major articles,

2. your recommendations of good authors, or,

3. your idea for a short essay.

Please help to define the future of our field with this exciting theme issue. 